\title{
A brief educational intervention changes knowledge and attitudes about long acting reversible contraception for adolescents in rural Ghana
}

\author{
Rachel Perry ${ }^{1 *}$, Marian Sharon Oteng ${ }^{2}$, Sadia Haider ${ }^{1}$ and Stacie Geller ${ }^{1}$ \\ ${ }^{1}$ Department of Obstetrics and Gynecology, University of Illinois at Chicago College of Medicine, Chicago, IL, US \\ ${ }^{2}$ University of Ghana, Accra, Ghana
}

\begin{abstract}
Knowledge and attitudes about adolescent childbearing, contraception, and long acting reversible contraception (LARC) were assessed among 52 female adolescents and 48 parents of female adolescents in Manso Nkwanta, Ghana, before and after an educational intervention. The 30-minute intervention addressed safety and effectiveness of contraception, with emphasis on intrauterine devices and contraceptive implants (LARC methods). The survey was designed to evaluate knowledge and attitudes toward adolescent pregnancy, contraception, and education of adolescent females. Baseline knowledge of the medical and social risks of adolescent childbearing were high, but only $61 \%$ of adolescents and $54 \%$ of parents knew that contraception was safe for adolescents. Adolescents and parents both improved in LARC knowledge, and more participants had positive attitudes toward LARC compared to baseline after the intervention. A brief, focused educational intervention can improve knowledge and create favorable attitudes toward LARC.
\end{abstract}

\section{Introduction}

Adolescent pregnancy is common in Ghana, similar to most Sub-Saharan African countries. The birth rate among 15-19 year old Ghanaians is 76 per 1000 [1]. Of sexually active unmarried 15-19 year old females surveyed in the 2014 Ghana Demographic and Health Survey, only $31.5 \%$ were using a modern method of contraception. Most adolescent pregnancies are unintended, with $42 \%$ of women under age 20 stating their births were planned, versus $69 \%$ of births overall in Ghana [1].

Unintended pregnancy may lead to unsafe abortion, which disproportionately affects adolescents in Sub-Saharan Africa; they account for $22 \%$ of unsafe abortions in the region [2]. Adolescents who continue their pregnancies are more likely to die in childbirth than women in their 20s and 30s [3]. Rural Ghanaian adolescents are more likely to have children than their urban counterparts, with a birth rate of 100 per 1000, compared to urban adolescents' rate of 53 per 1000 [1]. This differential puts rural adolescents at an unacceptably high risk of maternal morbidity and mortality.

Adolescent childbearing is also associated with poorer educational attainment. In Ghana, 23\% percent of adolescent females with no education have begun childbearing, versus $6 \%$ of adolescent females with a secondary education. Gender inequality exists in regard to completion of secondary school and university, with females less likely to achieve these higher levels of education than males; school dropout due to childbearing may play a significant role in this [1].

In Ghana, births to women less than 20 years old are associated with higher neonatal and child mortality compared to births to women between 20-29 years [1]. Rapid population growth is a concern in Ghana, as it is in other developing nations. Delaying age at first birth, therefore, is a strategy that could have a four-fold impact: decrease unintended pregnancy and unsafe abortion, decrease maternal and neonatal mortality, increase gender parity in education, and slow population growth.

The sexual education needs of Ghanaian adolescents, as implied by the high rate of unintended pregnancy, are not being met. While Ghanaian policy dictates that sexual education be taught in schools, only $61 \%$ of adolescents surveyed stated their school offered any sexuality education [4], suggesting that a gap exists between policy and practice. Additionally, there is a need for interventions that target outof-school youth.

The term long acting reversible contraception (LARC) denotes a category of the most effective reversible methods, intrauterine devices (IUDs) and contraceptive implants, both with failure rates of less than 1 per 100 couples per year. LARC methods should be considered firstline methods for adolescents (Ott \& Sucato, 2014). The objective of this study was to determine whether knowledge and attitudes about these most effective methods of family planning for adolescents in rural Ghana could be changed by a brief, community-based educational intervention aimed at adolescent females and parents of adolescent females.

\section{Materials/methods}

This study was conducted in the rural village of Manso Nkwanta, in the Amansie West district of Ghana. In this district 15\% of individuals

Correspondence to: Rachel Perry MD, MPH, UCI Medical Center Department of Obstetrics and Gynecology 101 The City Drive, South, Building 56, Suite 800, Orange, CA 92868; Tel: +1-714-456-6277; E-mail: rachel.perry@uci.edu

Key words: contraception, adolescent, family planning, education, developing countrystatus

Received: May 14, 2017; Accepted: May 29, 2017; Published: May 31, 2017 
live in poverty and $25 \%$ are non-literate (of literate individuals, $80 \%$ are literate in English) [5]. A district health clinic is located in Manso Nkwanta and family planning methods are provided through this clinic (including IUDs and contraceptive implants). Permission to conduct the study in this community was granted by the Chief and Queen Mother of the district. The study was IRB-approved by the University of Illinois at Chicago Institutional Review Board and by the Komfo Anokye Teaching Hospital Committee on Ethics in Kumasi, Ghana.

\section{Survey development}

A survey was developed to test knowledge and attitudes toward the following: 1) Risks of adolescent childbearing; 2) Family planning for adolescents, with emphasis on LARC methods; and 3) Education for adolescent females, particularly as it relates to childbearing. Twelve knowledge items and 14 attitude items were included. Nine items were modified from a study of US adolescents' knowledge and attitudes toward the IUD [6], and three items were modified from the National Longitudinal Study of Adolescent Health [7], surveys that have been used with and validated for US adolescents. The remaining 14 items were original and guided by conversations with stakeholders and community members from an April 2013 visit by the study team, as well as information from the Ghana Demographic and Health Survey [8]. The new items focused on the relationship between adolescent childbearing and educational attainment, as well as increased pregnancy risk for adolescents compared to adults. Items used a visual five-point Likert scale to accommodate non-literate individuals and ranged from 1 - Strongly Disagree (frowning face) to 5 - Strongly Agree (smiling face). Sample survey items are shown in Figure 1. Construct validity for the few items was established by consensus among three authors, who are obstetrician-gynecologists (RP, SH), and experts in global women's health (SH, SG). Face validity was established by consensus among all authors, including one of whom had lived in Manso Nkwanta as an adolescent (MO). The primary outcomes were change in knowledge and attitudes about LARC for female adolescents and parents of female adolescents after an educational intervention. Desired score on the knowledge scale was greater than $60 \%$ correct answers. The same knowledge and attitude items were used on the baseline and postintervention surveys.

\section{Recruitment}

Adolescent females aged 13-19 and parents of adolescent females aged 13-19 who resided in Manso Nkwanta were recruited. Participants had to speak and understand English or Twi, the primary tribal language spoken in the area, but did not have to be literate in either language. Purposive sampling was used to recruit half adolescents $(n=52)$ and half parents $(n=48)$. For adolescents, enrollment was stratified to approximately half adolescent mothers $(n=29)$ and half adolescents who had never given birth $(n=23)$. No attempts were made to recruit adolescent-parent pairs specifically, but neither was such a pairing a reason for study exclusion.

Recruitment occurred door-to-door, and if a member of a household was present, researchers asked whether a female of the target age lived there. If yes, the study was introduced to the adolescent and the parent(s). If the eligible persons were away, a member of the study team returned in the evening. 110 individuals were eligible, all 110 were enrolled, ten did not attend the intervention, and therefore a convenience sample of 100 individuals participated.

Informed consent was obtained from parents and adolescents aged 18-19 in their preferred language. Informed consent for participation of daughters under 18 was obtained from one parent and verbal assent was obtained from daughters. Participants were given 10 Ghana cedi (approximately $\$ 3.50$ in USD) in appreciation of their time upon completion of the study.

\section{Intervention}

The baseline survey, intervention, and post-intervention survey were conducted in a private meeting room in a community center in a single session, lasting approximately 90 minutes and administered to groups of 6-8 individuals. Groups consisted of one of the following demographics: adolescent mothers $(n=29)$, adolescents who had never given birth $(n=23)$, mothers $(n=32)$, and fathers $(n=16)$ of adolescent females. Groups were segregated in this manner to increase participant comfort with the topics discussed in the intervention. The surveys were read aloud by the research assistant to the group in English and Twi. Though survey questions were asked in the group setting, each individual recorded his or her answer on a paper survey covered by a folder to maintain confidentiality in the group setting. Prior to reading the questions regarding contraception methods, participants were instructed to answer "no opinion" if they had never heard of the method before. The baseline survey was administered immediately prior to the intervention, and the post-intervention survey was administered immediately after the intervention.

The 30-minute oral educational intervention included the following: 1) Adolescent development and sexual health (for example when females are able to get pregnant); 2) How family planning can increase educational opportunities for adolescents; and 3) Evidencebased safety and effectiveness information for all contraceptive methods available in the community (reviewing each method's mechanisms of action, duration, benefits, and risks). The intervention used the World Health Organization's (WHO) chart entitled "Comparing effectiveness of family planning methods" as a visual aid [9], as well as models of an IUD and a contraceptive implant. The intervention was developed with input by each author, of whom two are experts in contraception and family planning. Emphasis was placed on the most effective tier of methods appropriate for adolescents (IUD and implant), although all available methods were discussed. Dual pregnancy and HIV/STI prevention was discussed. Approximately 15 minutes of the session was didactic and 15 minutes was interactive with the participants, discussing their method-specific questions or talking about their personal experiences with contraception. The intervention was not tested before the study commenced.

\section{Data management and analysis}

Survey data were coded and entered into data management software and a second researcher checked entry. Data were analyzed with SAS 9.2, using descriptive, chi-square and t-test statistics. Likert scales were collapsed into agree (strongly or somewhat agree), disagree (strongly or somewhat disagree), and no opinion. There was no greater than $1 \%$ missing data on any single item, and no additional processes for handling missing data were employed in the analysis.

\section{Results}

\section{Demographics, reproductive and educational history}

The baseline characteristics of participants are shown in Tables 1 and 2. Adolescents had an average of 8.6 years of school. Adolescent mothers were less likely to be enrolled in school than those who had not given birth $(0 \%$ vs. $57 \%, \mathrm{p}<0.001)$. The majority of adolescents had used a method of family planning in the past (60\%), and the most 


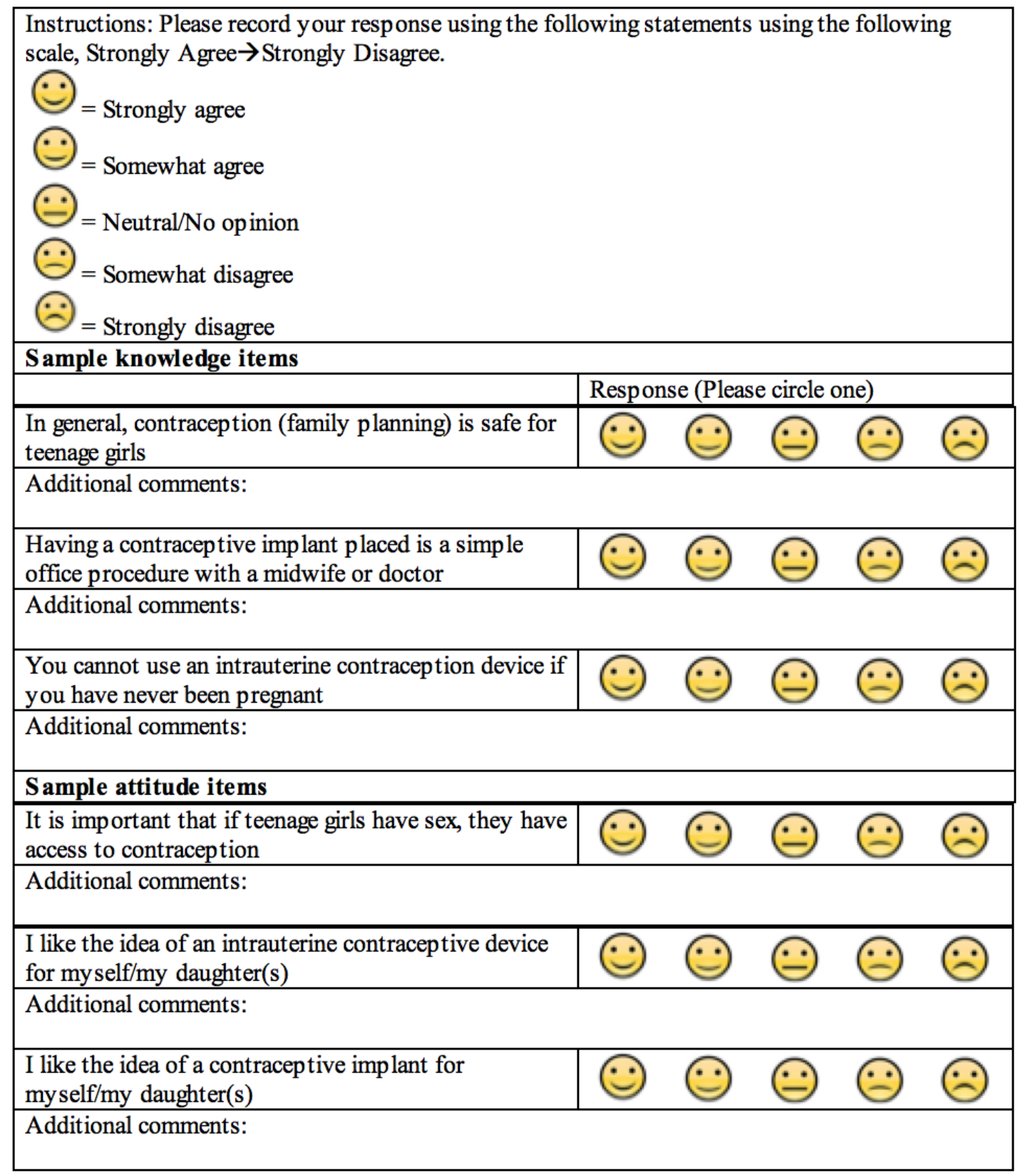

Figure 1. Sample survey items

common form of contraception ever used by adolescents was fertility awareness (31\%).

\section{Knowledge}

Baseline answers to knowledge items are shown in Table 3. The percent of correct LARC knowledge items (of 8) improved in adolescents $(8 \%$ to $63 \%, \mathrm{p}<0.001)$ and parents $(8 \%$ to $78 \%, \mathrm{p}<0.001)$ after the intervention (Figure 2).

\section{Attitudes}

Baseline agreement with attitude items is shown in Table 4. After the intervention, significantly more adolescents agreed with the statement "I like the idea of an IUD for myself" ( $2 \%$ to $27 \%, \mathrm{p}<0.001$ ) and "I like the idea of a contraceptive implant for myself" (15\% to
$60 \%, \mathrm{p}<0.001)$. Parents were also more likely to have positive attitudes toward IUD ( $2 \%$ to $83 \%, \mathrm{p}<0.001)$ and implant $(21 \%$ to $85 \%, \mathrm{p}<0.001)$ for their daughters after the intervention (Figure 3).

Adolescent mothers were marginally more likely to have a positive attitude toward the implant than adolescents who had never given birth $(69 \%$ vs. $48 \%, \mathrm{p}=0.13)$, but they were no more likely to have a positive attitude toward the IUD. Neither age nor school enrollment were correlated with positive attitudes toward IUD or implant.

\section{Discussion/conclusions}

Approximately 16 million births to adolescents aged 15-19 occur each year, of which $95 \%$ take place in low- and middle-income countries [10]. School dropout and decreased lifetime earnings for women are 
Table 1. Characteristics of female adolescents receiving educational intervention on family planning for teens in Manso Nkwanta, Ghana

\begin{tabular}{|c|c|}
\hline & $\mathrm{n}=52(\%)$ \\
\hline \multicolumn{2}{|l|}{ Age } \\
\hline $13-15$ & $12(23)$ \\
\hline $16-17$ & $13(25)$ \\
\hline $18-19$ & $27(52)$ \\
\hline \multicolumn{2}{|l|}{ Currently enrolled in school } \\
\hline Yes & $13(25)$ \\
\hline No & $39(75)$ \\
\hline \multicolumn{2}{|l|}{ Number of children } \\
\hline 0 & $23(44)$ \\
\hline 1 & $22(42)$ \\
\hline 2 & $7(14)$ \\
\hline \multicolumn{2}{|l|}{ Ever used contraception } \\
\hline Yes & $31(60)$ \\
\hline No & $21(40)$ \\
\hline \multicolumn{2}{|c|}{ Family planning methods used } \\
\hline Fertility awareness & $16(31)$ \\
\hline Condom & $8(15)$ \\
\hline Emergency contraception & $6(12)$ \\
\hline Injectable & $5(10)$ \\
\hline Oral contraceptive pill & $4(8)$ \\
\hline Implant & $3(6)$ \\
\hline Intrauterine device & $0(0)$ \\
\hline
\end{tabular}

Table 2. Characteristics of parents of female adolescents receiving educational intervention on family planning for teens in Manso Nkwanta, Ghana

\begin{tabular}{|l|l|}
\hline & $\mathrm{n}=48(\%)$ \\
\hline Age & $\mathrm{m}=47.2(\mathrm{SD} 11.3)$ \\
\hline Sex & $32(67)$ \\
\hline Female & $16(33)$ \\
\hline Male & $\begin{array}{l}\text { Has a daughter who is an adolescent } \\
\text { mother }\end{array}$ \\
\hline Yes & $17(35)$ \\
\hline No & $31(65)$ \\
\hline
\end{tabular}

associated with adolescent childbearing, as are adverse neonatal and maternal outcomes [11]. An effort to reduce unintended pregnancy among adolescents in developing countries is vital for the health of communities and the future of developing nations. One strategy that has been proposed to reduce adolescent pregnancy is to increase awareness and availability of LARC methods in these areas. This study demonstrated that a brief, community-based educational intervention in rural Ghana improved knowledge and changed attitudes toward LARC among female adolescents and parents of female adolescents.

While both adolescents and parents were knowledgeable about the medical and social risks of adolescent childbearing, baseline knowledge of the safety of contraception for adolescents and characteristics of LARC methods was low. Attitudes toward adolescent childbearing revealed that while parents believed that pregnant adolescents should stay in school, more than half of the adolescents felt that they should drop out. While both groups thought adolescents should return to school after giving birth, this was not reflected in the participants' own lives, with none of the adolescent mothers currently in school.

This study agrees with others that have shown a low level of knowledge regarding pregnancy prevention in Sub-Saharan African adolescents. A Nigerian study revealed that among adolescents enrolled in school, only $47 \%$ knew that pregnancy could occur from a first act of intercourse. Eighty-four percent reported that they believed sexuality education should be provided in school, but only $43 \%$ reported receiving any [12]. Another study of Nigerian adolescents in school showed that $74 \%$ had misconceptions or negative attitudes about contraception, and that a positive attitude toward contraception was associated with use [13].

The literature reflects success of previous attempts at educational interventions focused on adolescent pregnancy prevention in SubSaharan Africa. A community-based sexuality education program in Nigeria improved reproductive health knowledge among out of school adolescents [14]. An educational program for adolescents in Tanzania increased reproductive health knowledge, but did not change reproductive health attitudes [15].

This intervention studied was unique in that it was communitybased and was thus able to capture adolescents who had dropped out of school. By including parents, this study was able to understand and potentially impact messages about adolescent childbearing and contraception that may be taught at home. Parental attitudes toward LARC for adolescents were even more positive than adolescent attitudes after the intervention.

This intervention relied heavily on verbal communication and the WHO chart, thus making it useful for non-literate as well as literate individuals. This intervention was acceptable to members of this rural Ghanaian village, with both adolescent females and parents willing to

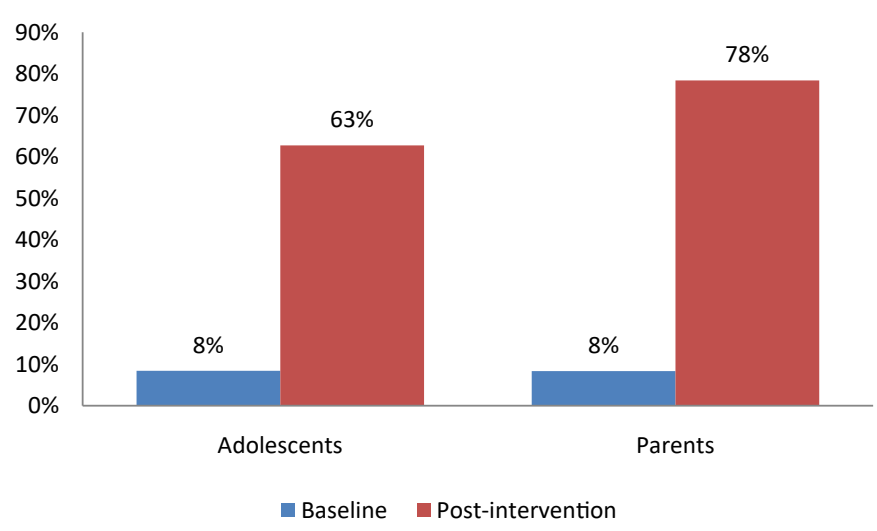

$* \mathrm{p}<0.0001$ for change in both groups

Figure 2. Mean percent of knowledge questions about long-acting reversible contraceptives (LARC) answered correctly among adolescents and parents before and after an educational intervention

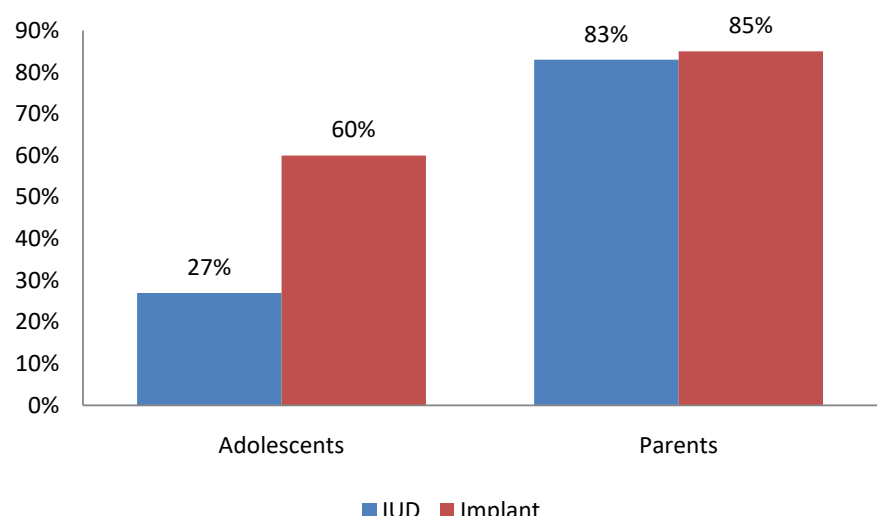

Figure 3. Percent of adolescents and parents with positive attitudes toward the intrauterine device (IUD) and contraceptive implant after an educational intervention (liking the idea of the method for themselves or their daughters) 
Table 3. Knowledge items correctly answered at baseline among rural Ghanaian female adolescents and parents of female adolescents

\begin{tabular}{|c|c|c|}
\hline & $\begin{array}{c}\text { Female } \\
\text { adolescents } \\
\mathbf{n}=52(\%)\end{array}$ & $\begin{array}{c}\text { Parents } \\
\text { of female } \\
\text { adolescents } \\
\mathbf{n = 4 8}(\%)\end{array}$ \\
\hline \multicolumn{3}{|l|}{ Social and medical risks } \\
\hline $\begin{array}{l}\text { Teen girls are more likely to die in childbirth than women in } \\
\text { their } 20 \text { s }\end{array}$ & $40(83)$ & $41(79)$ \\
\hline Most teenage girls who have a baby intended to get pregnant* & $37(77)$ & $42(81)$ \\
\hline $\begin{array}{l}\text { Teen girls are less likely to finish secondary school if they } \\
\text { become pregnant }\end{array}$ & $44(92)$ & $45(87)$ \\
\hline \multicolumn{3}{|l|}{ Contraception knowledge } \\
\hline In general, contraception is safe for teenage girls & $26(54)$ & $32(62)$ \\
\hline \multicolumn{3}{|l|}{ LARC knowledge } \\
\hline $\begin{array}{l}\text { In general, intrauterine contraceptive devices are safe for teen } \\
\text { girls }\end{array}$ & $2(4)$ & 2(4) \\
\hline In general, contraceptive implants are safe for teen girls & $8(17)$ & $7(14)$ \\
\hline $\begin{array}{l}\text { Having an IUD placed is a simple office procedure with a } \\
\text { midwife or doctor }\end{array}$ & $2(4)$ & $3(6)$ \\
\hline $\begin{array}{l}\text { Having a contraceptive implant placed is a simple office } \\
\text { procedure with a midwife or doctor }\end{array}$ & $2(4)$ & $9(17)$ \\
\hline You cannot use an IUD if you have never been pregnant* & $2(4)$ & $0(0)$ \\
\hline $\begin{array}{l}\text { You cannot use a contraceptive implant if you have never } \\
\text { been pregnant* }\end{array}$ & $6(13)$ & $3(6)$ \\
\hline It is necessary to remember an IUD every day* & $2(4)$ & $1(2)$ \\
\hline $\begin{array}{l}\text { It is necessary to remember a contraceptive implant every } \\
\text { day* }\end{array}$ & $8(17)$ & $10(19)$ \\
\hline
\end{tabular}

*false statements

Table 4. Agreement with attitude items at baseline among rural Ghanaian female adolescents and parents of female adolescents

\begin{tabular}{|c|c|c|}
\hline & $\begin{array}{c}\text { Female } \\
\text { adolescents } \\
\mathrm{n}=52(\%)\end{array}$ & $\begin{array}{c}\text { Parents } \\
\text { of female } \\
\text { adolescents } \\
\mathrm{n}=48(\%)\end{array}$ \\
\hline \multicolumn{3}{|l|}{ Attitudes toward teen childbearing and education for females } \\
\hline Teenage pregnancy is a problem in Manso Nkwanta & $44(92)$ & $51(98)$ \\
\hline It is important to protect teenage girls from pregnancy & $47(98)$ & $49(94)$ \\
\hline $\begin{array}{l}\text { It is important that teenage girls do not have sex until they are } \\
\text { married }\end{array}$ & $47(98)$ & $44(85)$ \\
\hline $\begin{array}{l}\text { It is important that if teenage girls have sex, they have access to } \\
\text { contraception }\end{array}$ & $46(96)$ & $42(81)$ \\
\hline $\begin{array}{l}\text { If a teenage girl becomes pregnant, it is wise for her to stop } \\
\text { going to school }\end{array}$ & $11(23)$ & $27(52)$ \\
\hline $\begin{array}{l}\text { It is more important for teenage boys to go to university than } \\
\text { teenage girls }\end{array}$ & $12(25)$ & $11(21)$ \\
\hline $\begin{array}{l}\text { If a teenage girl gives birth, it is important for her to return to } \\
\text { school }\end{array}$ & $46(96)$ & $48(92)$ \\
\hline $\begin{array}{l}\text { Teenage girls and boys should be taught about how to prevent } \\
\text { pregnancy in school }\end{array}$ & $46(96)$ & $48(92)$ \\
\hline In general, birth control is too expensive for teens to buy & $18(38)$ & $17(33)$ \\
\hline $\begin{array}{l}\text { It is hard for a teen girl to get her partner to use birth control } \\
\text { with her }\end{array}$ & $29(60)$ & $32(62)$ \\
\hline Using birth control is morally wrong & $12(25)$ & $26(50)$ \\
\hline \multicolumn{3}{|l|}{ Personal attitudes } \\
\hline $\begin{array}{l}\text { It is important for me/my daughter to avoid pregnancy right } \\
\text { now }\end{array}$ & $46(96)$ & $51(98)$ \\
\hline I like the idea of an IUD for myself/my daughter & $1(2)$ & $1(2)$ \\
\hline $\begin{array}{l}\text { I like the idea of a contraceptive implant for myself/my } \\
\text { daughter }\end{array}$ & $10(21)$ & $8(15)$ \\
\hline
\end{tabular}

participate in discussions about teen sexuality, and feasible to do in a community setting.

An important finding in this study is that more adolescents had positive attitudes toward implants than IUDs, as opposed to parents who had equally positive attitudes toward both methods. Hubacher, Mavranezouli \& McGinn (2008) established that increasing availability of implants is a strategy that could decrease maternal mortality in Sub-Saharan Africa. He points out that stakeholders are reluctant to invest in implants as they are more expensive than the other commonly available LARC method in the region, the copper IUD. This study indicates a much stronger interest among this group of rural Ghanaian adolescents in the implant over the IUD, supporting Hubacher, Mavranezouli \& McGinn's assertion that implants should be available and encouraged.

\section{Limitations}

This study had several limitations. The pre- and post-test study design is less robust for evaluating interventions than other designs such as randomized allocation to the intervention. Given the short follow-up period between pre- and post-intervention surveys, no inferences can be made about long-term knowledge acquisition nor long-term attitude change. Behavioral intention was not addressed with this study; thus no conclusions can be made about adolescents' likelihood to use the IUD or implant in the future to avoid unintended pregnancy.

Selection bias may exist in this study - those individuals with more favorable attitudes toward family planning for adolescents may have been more likely to participate. Additionally, purposeful equal sampling of adolescent mothers and those who have never had children make this study less reflective of the adolescent female population in this community than if random sampling had been employed. There is also the potential for response bias, particularly post-intervention, since the participants may have wished to give answers they thought the researchers wanted to hear based on intervention content. This study lacks a comparison group, and thus cannot conclusively determine that the intervention had a causal effect on knowledge and attitude change. These findings may not be generalizable beyond this setting in rural Ghana.

Despite its limitations, this study provides evidence that a brief educational intervention can be used for both adolescents and parents with similar success, and in a community setting. It also provides information about the knowledge and attitudes toward adolescent childbearing, contraception, and LARC in a rural Sub-Saharan African population. The information gathered from this study will allow further refinement of the intervention as well as the survey for future use and to expand the intervention to more individuals. Future research should address whether such community-based educational interventions result in behavior change or reduce adolescent pregnancy rates.

Multiple organizations have called for adolescents, particularly adolescent girls, to be given specific and urgent attention in the goal of improving health in developing nations [16]. An approach combining reproductive health education with programs to increase access to contraception, safe maternity care and abortion, and educational and employment opportunities for adolescent females has been recommended. Along these lines, the specific reproductive health needs of adolescents should be targeted. Efforts to increase uptake of long acting reversible contraceptives are fundamental in strategies aimed at improving the health and economic futures of adolescents in Sub-Saharan Africa.

\section{References}

1. Ghana Statistical Service, Ghana Health Service, \& ICF International. (2015). Ghana demographic and health survey 2014. (). Rockville, Maryland, USA 
2. Shah IH, Ãhman E (2012) Unsafe abortion differentials in 2008 by age and developing country region: High burden among young women. Reprod Health Matters 20: 169173 [Crossref]

3. Mangiaterra V, Pendse R, McClure K, Rosen J (2008) MPS notes: Adolescent pregnancy. World Health Organization.

4. Awusabo-Asare K, Biddlecom A, Kumi-Kyereme A, Patterson K (2006) Adolescent sexual and reproductive health in ghana: Results from the 2004 survey of adolescents. Occasional Report, Guttmacher Institute

5. Ghana Statistical Service (2014) 2010 population and housingcensus: Amansie west district.

6. Whitaker AK, Terplan M, Gold MA, Johnson LM, Creinin MD et al. (2010) Effect of a brief educational intervention on the attitudes of young women toward the intrauterine device. J PediatrAdolesc Gynecol. 23: 116-120 [Crossref]

7. Harris KM, Halpern CT, Whitsel E, Hussey J, Tabor J, et al. (2009) The national longitudinal study of adolescent health: Codebooks.

8. Ghana Statistical Service, Ghana Health Service, \& ICF Macro. (2009). Ghana demographic and health survey 2008 .

9. World Health Organization (WHO). (2011a). Comparing effectiveness of family planning methods. Family Planning: A Global Handbook for Providers

10. World Health Organization. (2016) Adolescent pregnancy. Retrieved from http://www. who.int/maternal child adolescent/topics/maternal/adolescent pregnancy/en
11. World Health Organization (WHO) (2011b). WHO guidelines on preventing early pregnancy and poor reproductive outcomes among adolescents in developing countries. Geneva: WHO Press.

12. Adeokun, LA, Ricketts OL, Ajuwon AJ, Ladipo OA (2009) Sexual and reproductive health knowledge, behaviour and education needs of in-school adolescents in northern nigeria. Afr J Reprod Health 13: 37-49. [Crossref]

13. Bassey EA, Abasiattai AM, Asuquo EE, Udoma EJ, Oyo-lta A (2005) Awareness, attitude and practice of contraception among secondary school girls in calabar, nigeria Niger J Med 14: 146-150. [Crossref]

14. Odeyemi KA, Onajole AT, Ogunowo BE, Olufunlayo T, Segun B (2014) The effect of a sexuality education programme among out- of- school adolescents in lagos, nigeria. Niger Postgrad Med J. 21: 122-127. [Crossref]

15. Madeni F, Horiuchi S, Iida M (2011) Evaluation of a reproductive health awareness program for adolescence in urban tanzania--a quasi-experimental pre-test post-test research. Reprod Health 8: 21. [Crossref]

16. PetroniS, Fritz, K (2013) Improving the health of women and adolescents: An unfinished agenda. New York: United Nations Department of Economic and Social Affairs.

17. Temin M, Levine R (2009) Start with a girl: A new agenda for global health Washington, DC: Center for Global Development.

Copyright: (2017 Perry R. This is an open-access article distributed under the terms of the Creative Commons Attribution License, which permits unrestricted use, distribution, and reproduction in any medium, provided the original author and source are credited. 